\title{
Application of Total Quality Management to Ensure Food Quality in Food Industry
}

\author{
Humaira Fayaz, Arvind Kumar , Firdous Kousar, Surbhi Sharma and Sunil Kumar \\ Division of Livestock Products Technology, Sher e Kashmir University of Agriculture Science and Technology, R.S. Pura, Jammu, \\ Jammu and Kashmir, INDIA \\ "Corresponding author: A Kumar; E-mail: drarvindlpt@gmail.com
}

Received: 12 March, 2020

Revised: 04 May, 2020

Accepted: 07 May, 2020

\begin{abstract}
Total Quality Management (TQM) is a managerial and managemental approach of an organization focused on quality, based on participation of all of its members and while aiming at long term benefits to the organization and consumers health. It is focused on continuous improvement of all processes approached with combined fundamental management techniques and specialized tools under quality systems. TQM is a process of managing the whole organization so that it progress in all the dimensions of products and services that are important to the consumers. It roots from the belief that mistake can be avoided or mininimised and defects can be prevented, with sole objective being the continuous process improvement. The introduction of Hazard Analysis Critical Control Point (HACCP) has signaled a shift in emphasis from resource intensive end product inspection and testing to preventive control of hazards at all the stages of food supply chain. It also identifies and controls hazards that are fundamentals for food safety. The integrated approach to implementation of ISO standards and HACCP concept is vital for management of quality and safety of dairy products hence safeguarding the customer's requirements, ensuring that certified products conform to minimum standards set internationally. These standards ensure and enhance transparency in the development of food quality and safety procedures, thus helping to upgrade and update food safety systems. ISO laid down guidelines, codes, specifications and requirements to evolve effective TQM system.
\end{abstract}

Keywords: Total quality management (TQM), HACCP, ISO, Food Safety, Quality.

In the present competitive environment, survival of the organizations depends on their ability to continuously improve and excel as per the expectations of the customers and consumers. Quality means meeting customer's expectations with changing scenario. Quality management means what the organizations do to enhance customer satisfaction and achieve continual up gradation of its performance. Management of quality summarized on five principal approaches to define quality as transcendent, product based, user based, based on manufacture, and based on its value. Another author defined quality as "conformance to requirements" (WHO, 2002). It is also defined as quality is about "fitness for use". Total quality management is an integrated effort to attain first and then sustain a high-quality service provided by an organization and further continuous improvement of process with error prevention at various levels and functions of an industry, aiming to meet and even surpass expectations and requirement of consumers (Gimenez-Espin et al., 2013). The basis of it can be traced back twentieth century when statistical theory was first applied to product quality control. The focus broadened from quality of products to quality of all issues related with it within an organization. The order of management is to attain business excellence by following inspection, quality control and statistical theory, total quality, total quality management, quality awards and excellence models and business excellence. The main is continuous quality improvement in the domain of product or service, employer-employee relations and consumer-

How to cite this article: Fayaz, H., Kumar, A., Kousar, F., Sharma, S. and Kumar, S. (2020). Application of total quality management to ensure food quality in food industry. J. Anim. Res., 10(3): 329-338. Source of Support: None; Conflict of Interest: None 
business relationships in an organization. (Karapetrovic and Willborn, 2002).

\section{TOTAL QUALITY MANAGEMENT}

Quality is a concept of "creation of worth for all stakeholders" and is a method of involvement of both management and employees in continuous improvement of the production of goods and services. It is a combination of quality and management tools aimed at increasing the business and reducing losses by adopting better practices. It is a systematic approach to the practice of management, requiring changes time to time in organizational processes, strategic priorities, individual's belief, attitudes and behaviors that combine with fundamental management techniques along with existing continuous improvement efforts and specialized tools under a well defined structure focused on continuously improving all processes (Ramnauth et al., 2008). It is based on all the members of an organization participating in improving processes, products, services and culture in which they work together. It views an organization as a collection of processes that focuses on the customer needs and expectations to enhance customer satisfaction and organization performance (Pozo et al., 2018). Performance measurement is not only a way of determining what has already happened in organizational set up, but it is also a way of getting people to act in ways that will bring about desired future outcomes and keeps on further progressing. Aligning performance measurement with organizational goals is in a way a challenge for the organization. Now a days, businesses are operating in very tough and grueling competitive environment facing internal customer satisfaction is a prerequisite to achieve external customer satisfaction. Customers are becoming more and more aware, demanding and desired products at ever lower prices (James et al., 2012). For all this there is a requirement of accuracy, timeliness, convenience, responsiveness, quality and reliability of the services offered by them. For this we further require an efficient supply chain management which is a network of supplier, manufacturing, assembly, distribution, and logistics facilities that perform the functions of procurement of materials, transformation of these materials into intermediate as well as finished products, and finally the distribution of these finished products to end use customers. It is mainly concerned with continuous improvement in all work, from high level strategic planning and decision- making, to detailed execution of work elements to fetch at consumer's goal (Yu et al., 2012). It emphasizes that mistakes can be avoided and defects can be prevented by constant vigil and management. Continuous improvement must not deal only with the improving the current results, but more importantly towards improving capabilities to produce better output in the future. The five major areas of focus for capability improvement are; demand generation, supply generation, technology, operations and people capability (Sivankalai and Yadav, 2012). The goal is "Do the right things right the first time, every time."

\section{Elements of total quality management (TQM)}

Leadership: It comprises of managerial vision, planning and support for implementation of leadership that establishes trust, equip and empower employees (Fig. 1). Top management commitment and participation in total quality management practices are the most important factors for the success of an organization. Managers should demonstrate more leadership than traditional management behaviors to increase employees' awareness of quality activities in adoption and practices. They must set clear, measurable and achievable objectives which will set the right direction for the firm. Once the specific objectives have been set and agreed upon, resources and capabilities can be employed to attain those approved objectives (Wickramasinghe, 2012; Trienekens and Zuurbier, 2008).

Employee involvement/Teamwork: Total employee involvement and teamwork can foster employee motivation and success through the opportunities to learn and to practice new skills. The increasing of workforce's knowledge, skills and motivation will lead the organization success (Evans, 2017). Make every people accountable, enable participation for continuous improvement to ensure people's abilities to be used and valued constantly. Strategic management is an approach to specify the organization objectives, to develop organization's policies, to determine plan in attaining the objectives, and to manage resources for policies and its implementation and enforcement (Mohamud et al., 2015).

Process approach: Desired results are more efficiently achieved when related resources and activities are viewed as a process, identifies linkages between processes in order to deploy resources effectively. The process approach involves product design quality and monitoring the process 
for constant and continuous improvement (Terziovski and Hermel, 2011).

Continuous Improvement: A concept that recognizes quality improvement is a journey with no end and that there is a need for continually looking for new approaches for improving quality for large gains that are accomplished by small sustainable improvements over a long time. In a total quality setting, in order to maintain and improve products and services, quality continually is a pace in achieving the primary purpose by system improvement continually (Goetsch and Davis, 2016).

Customer Focus on "Fitness for Use": It firms focus on serving the external customers by knowing the customers' expectations and requirements and then should offer the products/services, accordingly. The production can be arranged with respect to the customers' needs, expectations, and complaints by the aid of constant successful customer focus efforts. This encourages organization to produce high quality and reliable products/services on time with increased efficiency and productivity. It is one of four elements of total quality management that have a significant contribution to performances of an organization (Abusa and Gibson, 2011). They align organizational objectives with customer needs and expectations, design quality, specific characteristics of a product that determine its value in the marketplace. (Ahmad et al., 2019)

Supplier quality management: It implies in reducing and streamlining the supplier base to facilitate managing supplier relationships, developing strategic alliances with suppliers, working with suppliers to ensure that all expectations are met. It involves suppliers early in the product development process to take advantage of their capabilities and expertise. High quality inputs provide better products and/or services by enabling the suppliers to adopt quality management proceedings to deliver reliable and quality products and/or services timely (Luning et al., 2008).

Conformance quality: The degree to which a product meets its design specifications, manage performance measures by facts rather than gut feeling. Quality is first and schedules are second. It is one critical elements, in the success of overall implementation, which will elevate quality as a whole and improve business performance of an organization (Haque et al., 2014).

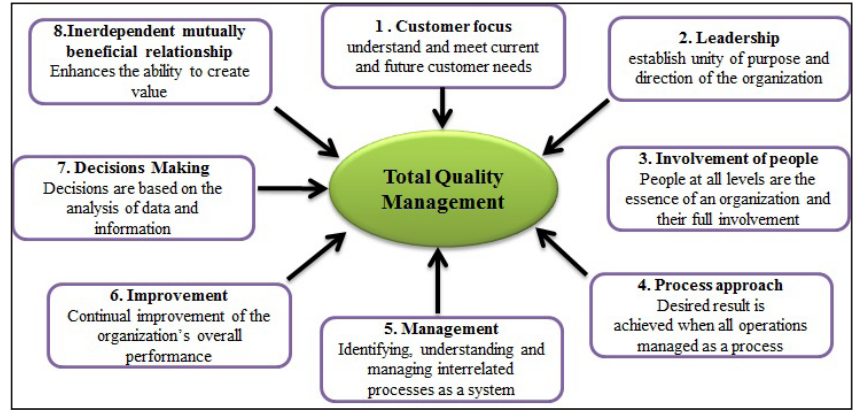

Fig. 1: Major principals of total quality management

\section{HAZARD ANALYSIS AND CRITICAL CONTROL POINTS (HACCP)}

It has been applied as an effective and rational method for guaranteeing food quality and food safety "from farm to fork" to ensure consumers health (Wallace et al., 2005). It can be used to comprehensively to analyze potential hazard factors which could cause food contamination physical, chemical and biological for the entire food industry supply chain. It was originally developed as a microbiological food safety system to assure food safety for astronauts by NASA as "zero defect foods" (Bertolini et al., 2007). It also referred as a preventive system that enabled manufacturers to produce foods with a high degree of assurance that the foods were produced safely and are wholesome in nature for customers. If the HACCP system is correctly implemented, there will be minimum requirement to test the final product. It has been further standardized by the Codex Alimentarius Commission, and, generally, is a preventive approach which identifies, maintains, evaluates, controls and monitors each production point that is significant for food safety (Wallace et al, 2014). It is a systemic procedure focused to identify hazards that may be of microbiological, physical or chemical nature, as early as food manufacturing and to eliminate these hazards by taking the suitable measures. This control system connects all the potential hazard points from producer to consumer food supply chain, and implements information collecting, transferring, storing, checking, and sharing among supply chain members in order to enhance the quality and safety of the food products. One of the key advantages of the concept is to enable any company to move away from a philosophy of control based on testing to a preventive approach, whereby potential hazards are identified and controlled in the manufacturing environment. Their main 
objective is to identify problems before they actually occur, establishing control measures against it that are critical to towards food safety at each and every stage of product processing (Cannas and Noordhuizen, 2008).

\section{Implementation of HACCP (prerequisite programme)}

Assemble the HACCPteam: Assembling a team consisting of individual with specific knowledge and expertise of process and product to be followed and developed respectively. It is the team's responsibility to develop the requisite programme that should be cross-functional and include individuals from all areas such as engineering, production and quality assurance.

Describe the food and its distribution: It consists of a general description of the product with respect to ingredients and processing methods. It should contain the following, as a minimum: name of product, food safety characteristics, ingredients used, packaging used, labeling requirements, storage and distribution, intended use, shelf life.

Intended use and consumers of the food: It should be based upon intended use by the end-user(s) or the target groups. It may be general public or a particular segment of the population (i.e. infants or elderly). The use of the food may be for direct consumption or as an ingredient in another food.

Description of process through flow diagram: It is to provide a clear and simple outline of all the steps involved in the manufacturing process, which are directly under the control of the establishment. In addition, it can include steps in the process, which are before and after the processing. Points to consider may include: all process steps where raw materials/ingredients and packaging are used, all raw materials or ingredients, all process steps in production, product recycle or rework loops, storage and distribution.

Verification the flow diagram: It should be reviewed periodically, modified, updated and documented, as necessary. It is recommended to take the diagram out to the production site and walk through the steps to ensure the diagram's accuracy. Prerequisite programme is an outline for the development and documentation that may include the following: identify mandatory or key prerequisites, write brief description, identify hazards reduced or eliminated, identify records maintained to verify reduced or eliminated hazard, identify staff responsible for maintaining records and written brief description of corrections.

\section{Principles of HACCP}

There are seven basic principles (Fig. 2) in establishing an effective HACCP plan, which is implemented together with the prerequisite programme (Taylor .and Taylor 2004; Fotopoulos et al., 2011).

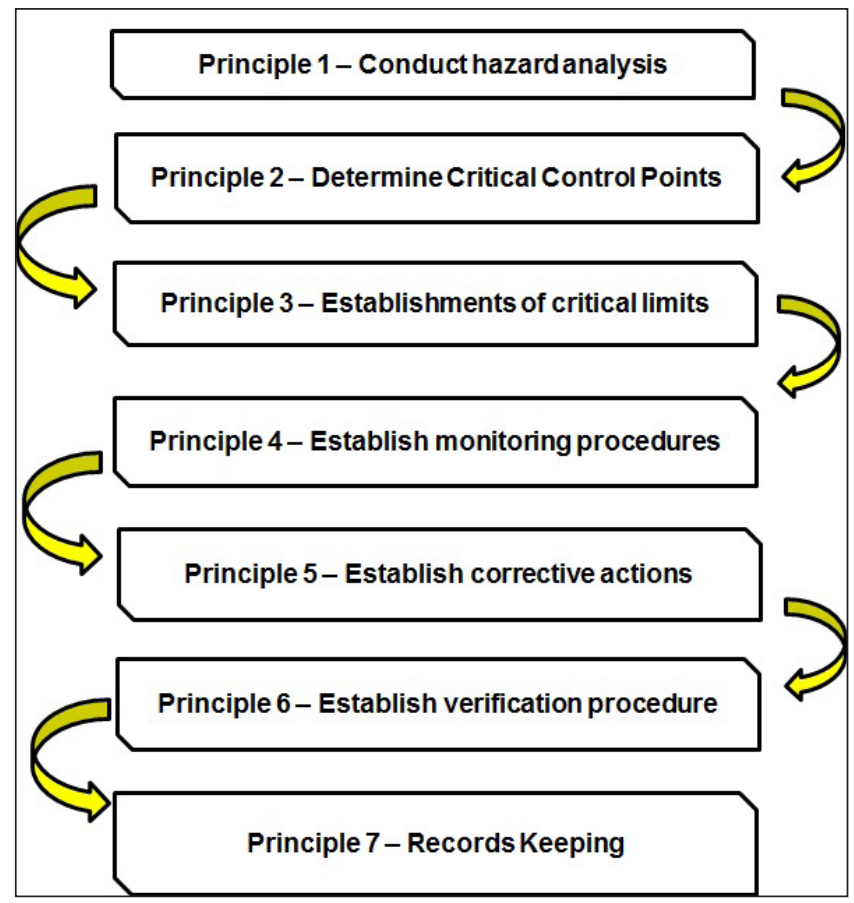

Fig. 2: Schematic representation of seven principals of HACCP

\section{Principle 1 - conduct hazard analysis}

A thorough hazard analysis addressing food safety hazards is the key to preparing an effective HACCP plan. The hazard identification and it's evaluation can be accomplish following three objectives namely: (a) The hazards are identified at each and every processing step (b) The hazards are evaluated to determine their severity and likelihood of occurrence affecting product quality (c) The hazard analysis provides a basis for determining management or control measures, need to be adopted as prerequisite programmes for managing quality of end 
product. It provides useful questions that can be used to identify and evaluate hazards: (a) Does the food product contains any ingredients that may present microbiological hazards, physical hazards or chemical hazards? (b) Does the food product permit survival or multiplication of pathogens and/or toxin formation in the food during processing? (c) Are there other similar food products in the marketplace? (d) What has been the safety record for these food products? (e) Does the process include a controllable processing step that destroys pathogens? (f) Is the food product commercially sterile? (g) Does the microbial population change during the normal time the food is stored prior to consumption? (h) Will the processing equipment provide the time-temperature control that is necessary for safe food product? (i) Whether the processing equipment be sufficiently monitored and controlled so the process will be within the tolerances required to produce a safe food product? (j) Are there any chances for food product contamination with any type of hazardous substances at any step?(k) Are there screens, sifters, thermometers, filters, etc., used to enhance consumer safety?(l) Who are to likely use the end products?

\section{Principle 2 - determine CCPs}

CCPs may vary depending on the hazard analysis, food plant organization, product and production method. Information developed during the hazard analysis should enable to identify which steps in the process are critical control points. Identification of each points can be facilitated by the use of the hazard analysis decision tree to be evaluated by experts.

\section{Principle 3 - establishments of critical limits}

A critical limit is used to differentiate between safe and unsafe operating conditions and these limits should not be confused with operational limits. Critical limits must be met to ensure the safety of the food products. These are parameters, which may be established as control measures.

\section{Principle 4 - establish monitoring procedures}

It is a planned sequence of observations or measurements used to assess whether a critical control points are under control, and an accurate record exists for future use in verification. It is essential to food product safety management in that it tracks the system's operation for any deviation occurs at the critical limit. It provides documentation for use in verification procedure because of the potentially serious consequences of a deviation from critical limits. The monitoring is possible with many types of physical and chemical methods. When it is not possible to monitor a critical limit on a continuous basis, it is necessary to establish the monitoring interval, which will be reliable enough to indicate the hazard is under control. Those individuals monitoring must be trained in the technique used to monitor each critical limit, fully understand the purpose and importance of monitoring.

\section{Principle 5 - establish corrective actions}

These are procedures to be followed when a deviation occurs because of variations in critical control points for different food products and the diversity of possible deviations, specific corrective action plans must be developed for each. It must demonstrate the points have been brought under control, i.e. within critical limits. Individuals, who have a understanding of the product processing, are to be assigned responsibility for taking corrective action. These procedures must be documented in the which may include: (a) elimination of the actual or potential hazards created by deviation (b) specific corrective actions, i.e. halt production of the product, isolate the affected product, return process to control and determine the disposition of the product involved and (c) methods to demonstrate that the CCP is brought under control, by determination of cause of deviation.

\section{Principle 6 - establish verification procedure}

Verification is addressed in two ways in the HACCP plan. First, establishing verification on the HACCP plan summary, and second, establishing internal verification monitoring. In both situations, documentation is critical. Verification is designed to ensure the monitoring programme is operating according to the requirements of programme. The verification format at this point is determined by team as to what actions will be taken in reference to deviations against CCPs. Once verification has been established, the internal verification monitoring programmes can be developed that should include (a) status of records associated with CCP monitoring, (b) direct monitoring data of the $\mathrm{CCP}$ during operation, (c) calibration 
and testing of monitoring equipments, (d) deviations and corrective actions taken against CCPs, (e) training and knowledge of individuals responsible for monitoring CCPs and ( $f$ ) check of chart to show the records have been verified. Internal verification monitoring can be utilized to ensure that the HACCP plan is functioning effectively that may include: a) establishment of appropriate verification monitoring schedules, b) review of the CCP monitoring records at specified frequency, c) visual verification of operations to observe if the CCPs are under control d) verify that changes have been implemented correctly after an HACCP plan has been modified e) review of consumer feedback records (Zu et al., 2009; Domenech et al., 2008).

\section{Validating the HACCP plans}

The HACCP team should conduct a validation of the HACCP plan when the process or product formulation is altered. The scientific processes to validate the HACCP plan, CCPs and critical limits are satisfactory to guarantee The addition, the validation process may need to be conducted if at all the verification process does not correct and address the hazard. The HACCP team should validate the plan by reviewing the following items: (a) effectiveness of the process (b) accuracy of the flow diagram (c) completeness of plan (d) soundness of the hazard analysis (e) appropriateness of the CCPs (f) scientific justification for the critical limits (g) comprehensiveness of the corrective actions (h) effectiveness of the monitoring programmes and the record keeping (Bas et al., 2007.).

\section{Principle 7 - records}

It is strongly recommended that an inventory of all records be completed and must be documented. This inventory summary is very useful in evaluating the programme to make sure all identified records have actually been created and utilized in the system. The HACCP plan may include the following: (a) listing of the team and assigned responsibilities (b) statement of intent (c) description of the product and its intended use (d)flow diagram for the entire manufacturing process indicating CCPs (e) monitoring system (f) corrective action plans for deviations from critical limits $(\mathrm{g})$ procedures for verification $\mathrm{h}$ ) records for all CCPs i) hazard analysis. (Mortimore and Wallace, 2013).
The following records must be available for review (Jin et al., 2008):

$\square$ Training records- documentation of human resource have been trained properly in their role in monitoring $\mathrm{CCP}(\mathrm{s})$ identified in the HACCP plan summary

$\square$ Processing records - records of monitoring of the CCPs are in place.

$\square \quad$ Deviation or corrective action log against any lag - documentation showing any deviation from a critical limit for a CCP strongly recommended.

$\square \quad$ Verification and validation records -records showing necessary validation has occurred and (b) records showing routine verification of control charts.

$\square$ Records showing any major changes to the original HACCP plan.

\section{Benefits of HACCP system}

Food safety is the primary concern in a food product. The wholesomeness and quality of the product may also be enhanced by implementation of HACCP programmes. The overall and specific benefits include: (a) focus on prevention (b) utilizes science-based food safety data and principles (c) provides a high level of assurance of food product safety (d) focuses appropriate technical resources and control on critical points in the production process (e) lessens emphasis on end product testing f) meets customer needs and expectations (g) increased consumer confidence in dairy products (h) assured brand integrity (i) decreased numbers of consumer complaints (j) reduced incidence of product holds and/or recalls $\mathrm{k}$ ) increased sales opportunities (Goetsch and Davis, 2016).

\section{ISO Standards}

Quality has taken a tangible form with the advent of ISO 9000 series of standards, in the pursuit of excellence. Organizations have been facing a strong and competitive market besides high customer expectations, what makes them to look for ways to stay competitive in the grueling market. To reach that, companies take every step to 
improve the activities that add can value to their adopted process and business (Lee et al., 2013). The search for excellence is intimately related to their products, services and processes quality and to achieve it maximally, many organizations opt for a Quality Management System (QMS) implementation, supported by several models and tools for getting successful (Fonseca, 2015).

ISO is an international independent, non-governmental standard setting body composed of representatives from various national standards organizations for regulating product uniformly worldwide. Therefore, it is recognized internationally as a benchmark for measuring quality. The "ISO" is the name refers to the scientific term "iso" meaning for equal. Thus, certified organizations are assured to have quality equal to their peers and the objective of ISO 9000 family of standards is to provide organizations with guidance and tools needed to ensure that their products and services meet external requirements for achieving the quality and drive consistent quality improvement. The ISO created the international standards which give specifications for products, services and systems, to ensure quality, safety and efficiency (Russel, 2000).

In order to improve and update food safety systems, the international standards enhance transparency in the development of food quality and safety procedures. (ISO 22000: 2005. food safety management system). The ISO 9001 standard, elaborated by the technical Committee of the International Standardization Organization, defines requirements to support organizations on the quality and conformity of their products and services, fulfilling customers' necessities efficiently (Fonseca and Domingues, 2017).

\section{ISO 9000 series standards structure}

The ISO 9000 family contains following standards: ISO 9001:2015: quality management systems requirements, ISO 9000:2015: QMS- fundamentals and vocabulary, ISO 9004: 2018: quality management, quality of an organization-guidance to achieve sustained success, ISO 19011:2018:guidelines for auditing management systems.

\section{History and revisions}

ISO 9000 was first published in 1987 that underwent two major revisions in 2000 and 2008, the most recent being ISO 9000:2015 and ISO 9001:2015. ISO 9000 is a series or family of quality management standards while ISO 9001 is a standard within the family. ISO 9001:2000 is a millennium standard. The current version is ISO 9001:2015 which was published in September 2015. ISO 9001:2015 is the latest version of ISO Quality Management System standard. If ISO 9001:2008 emphasizes on continual improvement and customer satisfaction, ISO 9001:2015 puts more focus on risk-based thinking and attitude. Risk-based thinking is a concept which approach added a new version, requires organizations to identify and analyze potential risks that could arise both from inside and outside of the organizations. Thus, organizations can formulate strategies to prevent any impact of the risks and they can be expectantly more resilient and sustainable by accommodating the risks. Other changes in the new version are the consideration of the organizational stakeholders' needs, the importance of knowledge management and less emphasis on documentation (Fonseca, 2015).

\section{ISO standards development process}

Proposal stage: A proposal is submitted to ISO by industry members who feel that an international standard is needed for their products or services. ISO forms technical committee and subcommittee to discuss and vote on the proposal and if vote is accepted standard moves to the second stage.

Preparatory stage: A group of experts is gathered and is put under the charge of a project chairman. The experts pen and revise a working draft that outlines the technical specifications that must be met by the standard and the document is sent to parent committee for review and if required may propose new changes.

Committee Stage: The working draft is registered by the central secretariat if ISO and circulated among the groups formed for the enforcement of standard. The committee reviewing the draft can vote to send the document to the next stage as draft international standard or revise the document.

Enquiry stage: It is circulated among member bodies if ISO for review, vote and comment. Member bodies have 5 months to respond. If $2 / 3^{\text {rd }}$ of committee members and $3 / 4^{\text {th }}$ of member bodies of ISO approve, it is approved and if voting requirements are not met, the draft is returned to committee stage for further revision. 
Approval stage: The final version is submitted for a second vote among the member bodies of ISO. They have 2 months to place their vote and is approved if $2 / 3^{\text {rd }}$ of members and $3 / 4^{\text {th }}$ of member bodies of ISO vote in the favour, then it got approved.

Publication stage: Minor editorial changes are made to final international standard which is then published by ISO. Within three years the new standard is reviewed and member bodies of the organization and revised if necessary (Zhang et al., 2012).

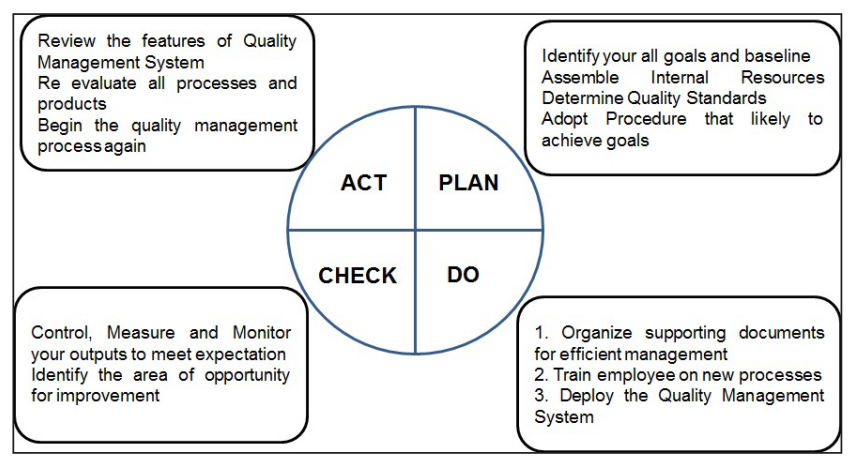

Fig. 3

As per the requirements of international standard, an organization must establish, implement, maintain and constantly improve quality management system. The organization must determine which processes are required for the quality management system, their application in the organization and needs to: (a) determine process inputs and outputs; (b) determine the sequence and interaction of processes; (c) determine the criteria and methods needed to provide an efficient; (d) functioning of these processes and their management; (e) determine and ensure the resources needed to support processes; (f) assign process responsibilities and authorities; (g) plan and implement actions to address these risks; (h) evaluate processes and if necessary modify them; improve processes and quality management system (Criado and Calvo-Mora, 2009).

A continual improvement of the process and the system as a whole, within ISO standards 9001:2015, is achieved with the application of PDCA cycle with the focus on thinking based on the risk in order to use opportunities and prevent unwanted results. A brief summary of PDCA cycle:

Plan: Defining the goals of the system, all individual processes, and the resources needed to achieve results in accordance with user requirements and policies of the organization, along with identifying risks and opportunities;

Do: apply what is planned.

Check: monitor and measure the process and the resulting products, along with regular reporting of results.

Act: taking measures to improve performance, if necessary.

Requirements set in 9001:2015, PDCA cycle can be applied to all processes and to the quality management system as a whole (IOS, 2009; Tunalioglu et al., 2012).

\section{Characteristics of ISO standards}

Generic in nature that it can be applied to any organization in any sector of activity. It does not matter an organization is or what type of industry it is service or manufacturing, one people or one million people, it is applicable to all.

$\square \quad$ Not a product standard that there is no product acceptance criteria in ISO hence we cannot inspect a product against the standard we can only however question whether a particular product has a certain record, an identity, inspection status, etc., but any non conformance are with the quality system and not the product. The requirements and recommendations apply to organizations that supply the product or services and hence affect the manner in which products or services are designed, manufactured, delivered, installed, processed etc (Deng et al., 2010).

$\square \quad$ Not a personal standard; a person cannot get certified to ISO, instead an organization or company becomes certified.

$\square \quad$ No such thing as ISO certified: only ISO is certifiable as it is the standard that defines the requirements of having quality management system and therefore, ISO is the only certifiable standard.

$\square \quad$ Not a membership group as an organization can not join ISO instead can follow the quality management standards under ISO (Aggelogiannopoulos et al., 2007). 


\section{ISO Certification}

To become ISO certified, an organization must follow the steps and requirements to implement an ISO quality management system, and then a certification body audits the performance management of organization as per the latest version of ISO requirements (CAC, 2001; WHO,2012). On passing the audit, the certifying body or registrar issues an ISO certificate for three years period. Finally the organization must be recertified every three years to maintain their ISO certification status.

\section{CONCLUSION}

TQM is a holistic and ethical approach of the firms to continuously improve their products or services or processes involving all stakeholders in order to satisfy their customers and to improve performance and sustainability. The results give that overall TQM practices improve all performance measures. Quality system of processing industries must apply the current regulations and guarantee the compliance of specifications indicated by customer. Industries can be tougher from the quality point of view by means the application of ISO Standards whose compliance provides confidence and positioning with respect to other companies. One of the most relevant parts when developing a HACCP consists in the identification and classification of hazards and analyzes possible incidences and correcting measures. A regulatory law implementation in livestock product processing and long term planning is required to achieve consumer safety.

\section{REFERENCES}

Abusa Fuzi. 2011. TQM Implementation and its Impact on Organizational Performance in Developing Countries: A Case Study in Libya. PhD Thesis. University of Wollongong.

Abusa, F. M. and Gibson, P. 2011. TQM implementation in developing countries: a case study of the Libyan industrial sector. Benchmarking: An Int. J., 20(5): 693-711.

Ahmad, A., Khaled, A., Mohammad A.L., Jais, A.A.A. and Ibrahim, R. 2019. Budget hotels' online guest reviews regarding customer satisfaction. J. Social Sci. Res., 5(2): 522- 534.

Aggelogiannopoulos, D., Drossinos, H. and Athanasopoulos, P. 2007. Implementation of a quality management system according to the ISO 9000 family in a Greek small-sized winery: a case study. Food Control, 18(9): 1077-1085.
Bas, M., Yoksel, M. and Havuooflu, T. 2007. Difficulties and barriers for the implementing of HACCP and food safety systems in food businesses in Turkey. Food Control, 18(2): 124-130.

Bertolini, M., Rizzi, A., Bevilacqua, M. 2007. An alternative approach to HACCP system implementation. J. Food Eng., 79(4): 1322-1328.

Cannas, J. and Noordhuizen, J. 2008. Consumer safety and HACCP-like quality risk management programs on dairy farms: the role of veterinarians. The Open Vet. Sc. J., 2: 3749.

Chandan R.C., Kilara A. and Shah N.P. 2008. Dairy processing and quality assurance, Wiley-Blackwell,

Codex Alimentarius Commission (CAC) 2001. Proposed draft revised guidelines for the application of the HACCP system in small and/or less developed businesses (SLDBs). Joint FAO/WHO Food Standards Programme Codex Committee on Food Hygiene, report of the 34th session, item 10, CX/ FH 01/10.

Criado, F. and Calvo-Mora, A. 2009. Excellence profiles in Spanish firms with quality management systems. Total Qualty Manage., 20(6): 655-679.

Deng, W., Sung, M. and Huang, H. 2010. The influence of quality management culture, quality consciousness, and service behavior for operating efficiency. The Business Review, Cambridge, 15(2): 152-157.

Domenech, E., Escriche, I. and Martorell, S. 2008. Assessing the effectiveness of critical control points to guarantee food safety. Food Control, 19(6): 557-565.

Evans, J.R. 2017. Quality \& Performance Excellence: Management, Organization, and Strategy (8th Ed.). Boston, USA: Cengage Learning.

Fonseca, L.M. and Domingues, J.P. 2017. How to succeed in the digital age? Monitor the organizational context, identify risks and opportunities, and manage change effectively. $J$. Manage. Market., 12: 443-455.

Fonseca, L.M. 2015. From quality gurus and TQM to ISO 9001:2015: a review of several quality paths. Int. J. Qlty Res., 9: $167-180$.

Fotopoulos, C., Kafetzopoulos, D. and Gotzamani, K. 2011. Critical factors for effective implementation of the HACCP system: a Pareto analysis. British Food J., 113(5): 578-597.

Gimenez-Espin, J.A., Jiménez-Jimenez, D. and Martinez-Costa, M. 2013. Organizational culture for total quality management. Total Quality Management and Business Excellence, 24(5-6): 678-692.

Goetsch, D. L. and Davis, S. B. 2016. Quality Management for Organizational Excellence: Introduction to Total Quality Management. $8^{\text {th }}$ ed., New Jersey: USA, Prentice Hall. 
Haque, A., Sarwar, A. and Azam, F. 2014. Total quality management practices in the Islamic banking industry: comparison between Bangladesh and Malaysian Islamic bank. Int. J. Ethics Soc. Sc., 2(1): 1-6.

International Organization for Standardization (IOS) 2009. ISO/ TS 22002-1:2009 Prerequisite programmes (PRP) on food safety - Part 1: Food manufacturing. IOS, Switzerland, Geneva.

James, O. M., Copuroglu, G. and Fred, A. F. 2012. Total Quality Management in Ghana: Critical Success Factors and Model for Implementation of a Quality Revolution. Journal of African Business, 13(2): 123-129.

Jin, S., Zhou, J. and Ye, J. 2008. Adoption of HACCP system in the Chinese food industry: a comparative analysis. Food Control, 19(8): 823-828

Lee, C.K.M., Lv, Y. and Hong, Z. 2013. Risk modelling and assessment for distributed manufacturing system. Int. J. Prod. Res., 51: 2652-2666.

Luning, P., Bango, L., Kussaga, J., Rovira, J. and Marcelis, W. 2008. Comprehensive analysis and differentiated assessment of food safety control systems: a diagnostic instrument. Trends Food Sci. Technol., 19(10): 522-534.

Mohamud, G.Y., Muhamud, A.S. and Mohamed, B.H. 2015. The relationship between strategic management and organizational performance in Mogadishu-Somalia. Eur. J. Res. Reflec. Manage. Sci., 3(2): 42-51.

Pozo, H., Barcelos, A.F., Kazue, A.G. 2018. Critical factors of success for quality and food safety management: Classification and Prioprization. Univ. J. Ind. Bus. Managem., 6(2): 30-41.

Ramnauth, M. Driver, F. and Vial, P. B. 2008. Food safety management in the fish industry in Mauritius: knowledge, attitude and perception. British Food J., 110(10): 989-1005.

Russel S. 2000. ISO 9000:2000 and the EFQM excellence model: Competition or co-operation? J. Total Qual. Manage., 11(4-6): 657-665.

Taylor, E. and Taylor, J. 2004. Using qualitative psychology to investigate HACCP implementation barriers. Int. J. Env. Health Res., 14(1): 53-63.
Terziovski, M. and Hermel, P. 2011. The Role of Quality Management Practice in the Performance of Integrated Supply Chains: A Multiple Cross-Case Analysis. The Quality Mgt. J., Milwankee, United States, Milwaukee, 18(2):10-25.

Trienekens, J. and Zuurbier, P. 2008. Quality and safety standards in the food industry, developments and challenges. Int. J. Prod. Econom. Amsterdam, Switzerland, Amsterdam, 113(1): 107-113.

Tunalioglu, R. Cobanoglu, F. and Ayse, D.K. 2012. Defining economic obstacles to the adoption of food safety systems in table olive processing firms. British Food J., 114(10): 14861500 .

Wallace, C.A., Powell, S.C. and Holyoak, L. 2005. Development of methods for standardised HACCP assessment. British Food J., 107(1): 723-742.

Wallace, C.A., Holyoak, L., Powell, S.C. and Dykes, F.C. 2014. HACCP - The difficulty with hazard analysis. Food Control, 35: $233-240$

Wickramasinghe, V. 2012. Influence of total quality management on human resource management practices. The International Journal of Quality \& Reliability Management, Bradford, United Kingdom, Bradford, 29(8): 836-850.

Word Health Organization (WHO) 2002. WHO Global strategy for food safety: safer food for better health. Geneva, Switzerland.

Word Health Organization. 2012. Baseline information for food safety policy and measures. October 2011, site:www.who.int/ foodsafety/foodborne_disease/ferg/ en/, Accessed on May $16 / 2015$.

Yu, B.T.W., To, W.M. and Lee, P.K.C. 2012. Quality management framework for public management decision making. Management Decision, United Kingdom, 50(3): 420-438.

Zhang, D., Linderman, K. and Schroeder, R.G. 2012. The moderating role of contextual factors on quality management practices. J. Operat. Managem., 30(1-2): 12-23

$\mathrm{Zu}$, X. 2009. Infrastructure and core quality management practices: How do they affect quality? The Int. J. Qual. Reliability Managem., 26(2): 129-149 